Discussion Paper No. 14-086

Combining International Cap-and-Trade with National Carbon Taxes

Peter Heindl, Peter J. Wood, and Frank Jotzo

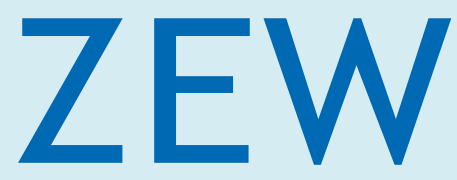

Zentrum für Europäische Wirtschaftsforschung $\mathrm{GmbH}$

Centre for European

Economic Research 
Discussion Paper No. 14-086

\title{
Combining International Cap-and-Trade with National Carbon Taxes
}

\author{
Peter Heindl, Peter J. Wood, and Frank Jotzo
}

Download this ZEW Discussion Paper from our ftp server:

http://ftp.zew.de/pub/zew-docs/dp/dp14086.pdf

Die Discussion Papers dienen einer möglichst schnellen Verbreitung von neueren Forschungsarbeiten des ZEW. Die Beiträge liegen in alleiniger Verantwortung der Autoren und stellen nicht notwendigerweise die Meinung des ZEW dar.

Discussion Papers are intended to make results of ZEW research promptly available to other economists in order to encourage discussion and suggestions for revisions. The authors are solely responsible for the contents which do not necessarily represent the opinion of the ZEW. 


\title{
Combining International Cap-and-Trade with National Carbon Taxes
}

\author{
Peter Heindl* \\ Centre for European Economic Research (ZEW) \\ heindl@zew.de \\ Peter J. Wood \\ Australian National University (ANU) \\ drwoood@gmail.com \\ Frank Jotzo \\ Australian National University (ANU) \\ Centre for European Economic Research (ZEW) \\ frank.jotzo@anu.edu.au \\ Chapter prepared for the book \\ “Emissions Trading as a Policy Instrument” \\ (MIT Press)
}

November 2014

\begin{abstract}
This paper examines the effects of combining an international cap-and-trade scheme with national carbon taxes. We consider a two-country stochastic partial equilibrium model with log-normally distributed uncertainty. The situation is analogous to the situation where European countries impose national carbon taxes in addition to the EU emissions trading. The allowance price in the joint cap-and-trade scheme depends on the tax rate, the relative size of countries and abatement options, the magnitude of uncertainty, and correlation of abatement costs. In most cases, the additional tax will not lead to additional production of the public good beyond the fixed targets. The additional tax results in higher costs of abatement to the country introducing the additional tax, and higher costs overall.
\end{abstract}

JEL-classification: Q53; H23; H41

Keywords: prices vs. quantities; linking; cap-and-trade; carbon tax; uncertainty; EU Emissions Trading Scheme

Acknowledgements: We are grateful for funding by the Deutscher Akademischer Auslandsdienst (DAAD) and the Group of Eight (Go8) through the Go8 Joint Research Cooperation Scheme. The research has further received funding from the European Community's Seventh Framework Programme under Grant Agreement No. 308481 and also from the Australian Research Council (DP110102057). Such support does not imply agreement with the views expressed in this paper. We are grateful for comments by Timothy Fitzgerald and participants at the CESifo Summer Institute 2013 "Emissions Trading Systems as a Climate Policy Instrument", organised by Marc Gronwald and Beat Hintermann.

* Corresponding Author: Peter Heindl, Centre for European Economic Research (ZEW Mannheim), e-mail: heindl@zew.de, phone: +49-621-1235-206, fax: +49-621-1235-226. P.O. Box 103443, 68034 Mannheim, Germany. 
This paper examines linkages of price and quantity instruments for reductions in emissions. Regulation by prices is introduced as an additional tax on top of regulation by quantities. The model builds on a more general analysis of price-quantity linking for public good provision in Wood et al. (2013).

We assume that two countries are covered by a joint cap-and-trade scheme and aim to comply with their respective targets for emissions levels, which are below expected businessas-usual emissions. In addition to the cap-and-trade scheme a tax is levied in country 1, on top of the cap-and-trade price. Allowances (or permits) are fully tradable, so compliance with the emissions targets occurs in aggregate: if one country reduces its emissions below the target, the other country can stay above its target, and the difference is accounted for by permits traded between the two countries. We take uncertainty in the cost of public good production into account by applying log-normally distributed error terms to the countries' cost functions.

Situations as modeled in this paper occur in practice. A prominent example is the EU Emissions Trading Scheme. The EU ETS is a joint cap-and-trade scheme of 27 EU member states, Norway, and Liechtenstein. Exogenous abatement targets are implicitly given by the countries' commitments to reduce emissions-for example, by the EU burden-sharing agreement (EU, 2002). In addition to the joint trading scheme, some countries introduced additional policies. Examples are the UK “price floor,” which works as an additional charge on emissions for the UK power sector, to bring the effective carbon price to a predetermined minimum level (Toke, 2011); carbon taxes that have existed in several European countries in parallel to the EU ETS (OECD, 2013); as well as the many non-pricing policies that exist in different countries, such as the German renewable feed-in tariff system (IEA, 2013). We model the partial equilibrium effect of such policies on prices, costs, and abatement in a joint trading scheme. 
The existence of a "single price" on some externality is a condition for efficiency in many situations. If firms minimize costs, and if there are no market distortions, marginal costs will be equated among all sources of emissions given the single price, which is a least-cost solution (Baumol and Oates, 1988, 1971; Baumol, 1972; Montgomery, 1972). Thus it is to be expected that the overall cost of reducing emissions is higher if the marginal cost of abatement effort differs between countries. This has been shown in general equilibrium modeling exercises such as those conducted by Böhringer at al. (2009a), who suggested that the overlapping instruments and multiple targets of the EU approach will lead to excess cost against a first best situation; by Böhringer et al. (2009b), who showed that additional policies (i.e., multiple carbon prices) will likely increase the overall cost of greenhouse-gas mitigation in the EU considerably; and Boeters and Koornneef (2011), who examined the likely cost of the EU renewable energy target, which is a separate element of the EU 2020 climate strategy, in parallel to the emissions-reduction target.

It is important to note that the single price that would result from an emissions trading scheme need not necessarily equal the "Pigouvian" price that equates the marginal cost of abatement with its marginal benefit. In practice the social costs of an externality such as greenhouse-gas emissions are difficult to assess (Baumol, 1972). It may be that additional policies beyond the EU ETS, such as the UK carbon price floor or the German renewable feed-in tariff scheme, reflect different views about acceptable or appropriate levels of externalities or costs of emissions abatement. In this paper, we set aside questions of the (social) optimality of emissions abatement targets, and instead focus on the distribution of costs of achieving some policy target. Our model is stochastic, allowing assessment of the probability distribution of different outcomes for costs, and thus an assessment of cost risks alongside expected values. Our modeling omits general equilibrium effects which can be of importance for assessments of actual (social) cost under different revenue recycling regimes or given pre-existing taxes (Bovenberg and Goulder, 1996; Bovenberg and van der Ploeg, 
1994; Bovenberg, 1999). Different revenue recycling regimes can also have major implications for first-best instrument choice (Pezzey and Jotzo, 2012).

We show that an additional tax levied in one country will increase the country's cost of producing the public good, decrease the others country's cost, and increase overall costs. This is because of differences in marginal abatement costs. The allowance price in the joint cap-and-trade scheme will decrease as result of the tax relative to a situation without the extra tax. The relative size of countries and the magnitude and correlation of uncertainty are important determinants for the actual effect of the tax on the allowance price and total costs. Additional abatement generated by the tax will only occur in cases when all abatement is generated by the tax and exceeds the joint quantity target of public good production of both countries. This represents a corner solution in which the cap-and-trade allowance price equals zero. Expected costs can be far higher in this situation than in the case of pure cap-and-trade without the tax.

\section{The model}

The model considers two countries (or, alternatively, regions, sectors, or firms) which are jointly covered under quantity regulation by cap-and-trade. Each country has an emissions target, and needs to reduce its emissions below some business-as-usual level. This can be described as each country having been allocated the production of a quantity of a public good (e.g., emissions reductions), denoted by $Q_{i}$. The production of the good incurs costs, which are ex-ante uncertain. Country 1 or country 2 produces abatement $q_{i} \geq 0$ at costs $c_{i}$, so that

$c_{i}=c_{i}\left(q_{i}, \theta_{i}\right)$

where the random variable $\theta_{i}$ influences the costs for country $i{ }^{1}$

\footnotetext{
${ }^{1}$ Modeling uncertainty under price and quantity-based emissions control as a random change in the slope of the marginal abatement cost curve is in the tradition of Weitzman (1974) and the subsequent literature, and we
} 
Cost functions are continuous and twice differentiable. Partial derivatives of country i’s cost function with respect to $q$ satisfy

$c_{q}^{\prime}>0$

and

$c_{q}^{\prime \prime}>0$

\section{Pure cap-and-trade}

When both countries produce the amount of $Q_{1}+Q_{2}$ under a joint cap-and-trade scheme, and assuming that there are no distortions in the market, marginal costs will be equated. ${ }^{2}$

Allowances issued under cap-and-trade are fully tradable and it is assumed that there is full compliance with the quantity targets. The joint amount of the produced good equals the required quantity, so that $q_{1}+q_{2}=Q_{1}+Q_{2}$. If a is the amount of allowances sold from country 1 to country 2 (a can be positive or negative), the equilibrium market price for allowances $p^{*}$ satisfies

$p^{*}=c_{1}^{\prime}\left(q_{1}+a, \theta_{1}\right)=c_{2}^{\prime}\left(q_{2}-a, \theta_{2}\right)$.

Equation 1 characterizes the cost-minimizing allocation of abatement between the countries under cap-and-trade (in the absence of transaction costs, market power and preexisting distortions). The allowance price equals the marginal valuation of allowances by the countries. The amount of traded allowances is chosen so that abatement costs are minimized in each of the countries. A country will sell allowances as long as marginal revenues from

follow this convention. It would also be possible to model uncertainty about underlying emissions growth and thus the amount of effort required to meet any chosen emissions target, but this would complicate the analysis without providing additional insights.

${ }^{2}$ Transaction costs (Stavins, 1995), market power (Hahn, 1984; Sinn and Schmoltzi, 1981), and non-costminimizing behavior (Hahn and Stavins, 2011) are distortions under which marginal abatement costs might not be equated and a least-cost solution might not be achieved. 
selling allowances are larger than marginal costs of domestic public good production. A country will purchase allowances as long as allowances are sold on the market at cost below the marginal cost of producing the public good domestically. Thus, for a given vector of public good production $\left(Q_{1}+Q_{2}\right)$, there is a cost-minimizing price $p^{*}$ (Baumol and Oates, 1971). With a "market in emission licenses," the market will reach the cost-minimizing equilibrium (Montgomery, 1972).

In Figure 1, the equilibrium allowance price under cap-and-trade is given at point $\mathrm{A}$ where marginal costs of both countries are equated. Countries produce quantities $q_{1,2}^{*}$ at price $p^{*}$. In this case, no trading of allowances occurs.

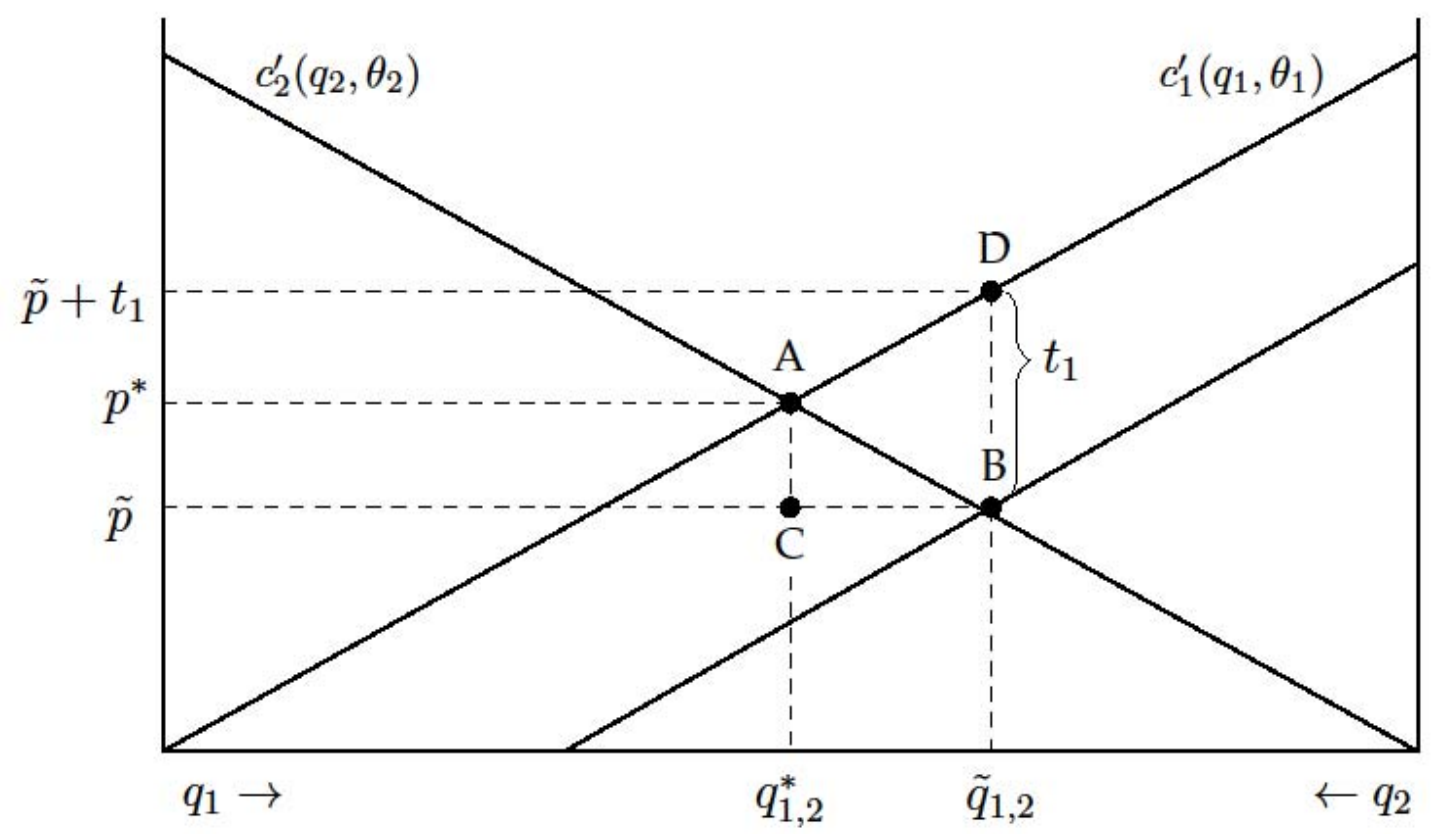

Figure 1: Marginal cost functions $c_{i}^{\prime}\left(q_{i}, \theta_{i}\right)$ and produced quantities of both countries $q_{i}$ (xaxis) with and without the tax introduced by Country 1.

Because marginal costs are equated between the countries, there are no options to further decrease the costs of producing the public good. If both countries choose the costminimizing quantities of the public good production $q_{i}^{*}$ so that it satisfies equation 1 and subject to the quantity constraint $q_{1}+q_{2}=Q_{1}+Q_{2}$ costs for each country are 
$C_{1}\left(\theta_{1}, \theta_{2}\right)=c_{1}\left(q_{1}^{*}, \theta_{1}\right)-p^{*} a$

and

$C_{2}\left(\theta_{1}, \theta_{2}\right)=c_{2}\left(q_{2}^{*}, \theta_{2}\right)+p^{*} a$.

The case of "pure" cap-and-trade as described in this section will serve as reference case in the model in the case of cap-and-trade with an additional tax in country 1 . Since a fully competitive cap-and-trade scheme with zero transaction costs is assumed as reference case, it is important to note that results could change considerably if these assumptions are relaxed. Market power of one of the parties engaged in trading will (in most cases) lead to a different allocation and distribution of cost than in the competitive case (Hahn, 1984; Sinn and Schmoltzi, 1981). Transaction cost, e.g., for allowance trading, will change the equilibrium allocation under cap-and-trade (Stavins, 1995).

\section{Additional unilateral tax by one country under cap-and-trade}

We now turn to the case where country 1 implements a policy to produce a larger amount of the public good domestically relative to the existing cap-and-trade scheme. To do so, an additional unit-tax $t_{1}>0$ on top of the allowance price under cap-and-trade is levied in country $1 .^{3}$ The tax results in production of the same tradable good, namely emissions reductions in country 1 , whether country 1 initially was a net exporter or a net importer of the good under the cap-and-trade regime. The price under cap-and-trade and the additional tax must satisfy

\footnotetext{
${ }^{3}$ This is the key difference between the model we use here and the one used in Wood et al. (2013), where it is assumed that country 1 only levies a tax and the price from the cap-and-trade scheme applied only in country 2.
} 
$\tilde{p}=c_{1}^{\prime}\left(\tilde{q}_{1}+a, \theta_{1}\right)-t_{1}=c_{2}^{\prime}\left(\tilde{q}_{2}-a, \theta_{2}\right)$.

The tilde denotes the cap-and-trade price and amounts of the public good provided if there is a tax, as distinct from the case without the additional tax above. Again both countries choose the optimal amounts of public good $\tilde{q}_{i}$ so that it satisfies equation 4 and subject to the quantity constraint $\tilde{q}_{1}+\tilde{q}_{2}=Q_{1}+Q_{2}$ at tax rate $t_{1}$.

The amount of public good produced by country 1 consists of two parts: one attributable to the tax and the other attributable to the permit price under cap-and-trade. If the allowance price under cap-and-trade was equal to zero, country 1 would still produce some amount of the public good by virtue of the tax. The additional quantity produced by country 1 in response to the tax is equal to distance $\mathrm{CB}$ in Figure 1 (in which the allowance price is positive).

The unilateral introduction of the tax by country 1 changes marginal conditions and, other things equal, leads to increased public good production in country 1 , so that $\tilde{q}_{1}>q_{1}^{*}$. Increased production by country 1 lowers the need for production by country 2 given the quantity constraint $Q_{1}+Q_{2}$, so that $\tilde{q}_{2}<q_{2}^{*}$. As a consequence, the allowance price under cap-and-trade decreases.

If $\tilde{q}_{1} \geq Q_{1}+Q_{2}$, there is no need for further public good production (emissions reductions) by country 2 . This is a corner solution in which all of the good is produced in country 1 . Country 1 values the public good by its marginal costs $c_{1}^{\prime}\left(\tilde{q}_{1}, \theta_{1}\right)=p+t$. It follows from (4) that for $\tilde{q}_{1} \geq Q_{1}+Q_{2}$, the allowance price is zero and country 2 acquires $Q_{2}$ from country 1 to fulfill its target. Costs in the corner solution are

$C_{1}\left(\theta_{1}, \theta_{2}\right)=c_{1}\left(\tilde{q}_{1}, \theta_{1}\right)$

and

$C_{2}\left(\theta_{1}, \theta_{2}\right)=0$. 
Alternatively, if $\tilde{q}_{1}<Q_{1}+Q_{2}$, there is need for further abatement in the joint capand-trade scheme. In this case, countries produce the amounts of $\tilde{q}_{i}$ of the public good which satisfies equation 4. From equation 4 it follows that a positive valuation is given to the tradable public good either by country 1 (given the tax) or by country 2 , so that $p^{*}>\tilde{p}>0$. Since countries are assumed to comply with their quantity targets $Q_{1}, Q_{2}$, the number of traded permits in the interior solution is $a=Q_{2}-\tilde{q}_{2} \cdot{ }^{4}$ Costs are

$C_{1}\left(\theta_{1}, \theta_{2}\right)=c_{1}\left(\tilde{q}_{1}, \theta_{2}\right)-\tilde{p} a$

and

$C_{2}\left(\theta_{1}, \theta_{2}\right)=c_{2}\left(\tilde{q}_{2}, \theta_{2}\right)+\tilde{p} a$.

Whenever $t_{1}>0$ with $\tilde{p}<p^{*}, \tilde{q}_{1}>q_{1}^{*}$, and $\tilde{q}_{2}<q_{2}^{*}$ overall cost of public good production exceed costs in the case of pure cap-and-trade. This is because

$\int_{q_{1}^{*}}^{\tilde{q}_{1}} c_{1}^{\prime}-\int_{\tilde{q}_{2}}^{q_{2}^{*}} c_{2}^{\prime}>0$

(In Figure 1, excess costs are represented by the area BAD.) In other words, the cost increases in country 1 cannot be fully offset by cost decreases in country 2 .

Because of the binding quantity constraint $Q_{1}+Q_{2}$, no additional amount of the public good (exceeding the amount that would have been produced under pure cap-and-trade) will be produced in the interior solution. Additional amounts of the public good will only be produced in the corner solution where $\tilde{q}_{1}>Q_{1}+Q_{2}$. In this case country 1 produces all of the public good and the produced quantity can exceed the cap-and-trade quantity constraint $Q_{1}+Q_{2}$

\footnotetext{
${ }^{4}$ Assuming compliance with the quantity targets is equivalent to assuming a "very high" compliance penalty in the emissions trading scheme in country 2.
} 
Figure 1 illustrates that the introduction of the tax in country 1 shifts public good production, so that country 1 produces more of the good vice versa the case of pure cap-andtrade $\left(q_{1,2}^{*}\right.$ to $\left.\tilde{q}_{1,2}^{*}\right)$. The introduction of the tax has two effects. Firstly, the effective price and the produced quantity in country 1 increase from A to D in Figure 1 . Secondly, the effective price and the quantity produced in country 2 decrease from A to $\mathrm{B}$. This drives a wedge between marginal abatement costs and causes excess costs equal to the area BAD. The two effects are not necessarily symmetric as in Figure 1. They depend on abatement cost parameters $\alpha_{i}$ of the countries relative to each other, targets $Q_{i}$, and uncertainty inherent in abatement cost functions. Below we examine the two effects by taking expectations over lognormally distributed "shocks" to abatement cost functions.

Under pure cap-and-trade, the price for allowances (y axis) is $p^{*}$ and equals marginal abatement costs of both countries (A). Countries produce quantities $q_{i}^{*}$. If country 1 unilaterally levies $t_{1}$ (distance $\mathrm{BD}$ ) on top of the allowance price, the allowance price will decrease to $\tilde{p}$. Country 1 will produce $\tilde{q}_{1}>q_{1}^{*}$ and country 2 will produce $\tilde{q}_{2}<q_{2}^{*}$. The taxinduced reallocation of public good production is equal to the distance $\mathrm{CB}$ and $\tilde{q}_{1}+\tilde{q}_{2}$ is equal to $Q_{1}+Q_{2}$. Overall costs will increase if country 1 introduces $t_{1}$ relative to pure capand-trade. Excess costs are represented by the area BAD. The overall quantity target $Q_{1}+Q_{2}$ is equal to the width of the $\mathrm{x}$ axis and equal to $q_{1}^{*}+q_{2}^{*}$ or $\tilde{q}_{1}+\tilde{q}_{2}$ respectively. The example shown in this figure is an interior solution. The marginal cost function of country 1 is shifted downward since functions are plotted in the space of cap-and-trade prices and quantities and country 1 would produce some of the good even if the cap-and-trade price (y axis) was zero. 


\section{Model parameterization}

To gain empirical insights into the issue under uncertainty, cost functions are parameterized. We use the same parameterization for cost functions as in Wood et al. (2013). Abatement cost functions for countries 1 and 2 are given by

$c_{i}\left(q_{i}, \theta_{i}\right)=\frac{1}{2} \theta_{i} \propto_{i} q_{i}^{2}$

where $\propto_{i}$ determines the slope of the marginal cost curves and is constant, $\theta_{i}$ is a random variable, and $q_{i}$ is the amount of the produced abatement.

It is assumed that the random variable $\theta_{i}$ is log-normally distributed and has a mean value of 1. Marginal costs are given by

$c_{i}^{\prime}\left(q_{i}, \theta_{i}\right)=\theta_{i} \propto_{i} q_{i}$

Assuming linear marginal costs keeps the analysis more tractable and has been standard procedure in the relevant literature (e.g. Hagem and Westkog 1998). Relative to abatement cost curves derived from empirical studies, linear marginal abatement costs will likely underestimate the increase in abatement costs as marginal costs increase, however this has no bearing on our qualitative results. ${ }^{5}$

In the interior solution, the number of allowances sold from country 1 to country $2, a$, will be the choice for which

$c_{1}^{\prime}\left(Q_{1}+a, \theta_{1}\right)+t=c_{2}^{\prime}\left(Q_{2}-a, \theta_{2}\right)$

and for the corner solution, $a=Q_{2}$. The minimum tax rate for which there is a corner solution is the tax rate for which the number of allowances (in the interior solution) is equal to $Q_{2}$. It

\footnotetext{
${ }^{5}$ Marginal abatement cost curves can be non-differentiable as shown by McKitrick (1999) and can have high inter- and intra-sectoral variance, as shown for the case of different air pollutants by Hartman et al. (1997), in which case simplifying assumptions are needed.
} 
follows that with the parameterization above, the number of allowances is given by the following equation.

$a=\left\{\begin{array}{cl}\frac{-\alpha_{1} \theta_{1} Q_{1}+\alpha_{2} \theta_{2} Q_{2}+t}{\alpha_{1} \theta_{1}+\alpha_{2} \theta_{2}}, & t<\alpha_{1} \theta_{1}\left(Q_{1}+Q_{2}\right) \\ Q_{2} & \text { otherwise. }\end{array}\right.$

The allowance price is equal to the marginal cost for country 2 to produce the amount $Q_{2}-a$ of abatement, and is given by the following equation.

$p=\left\{\begin{array}{cl}-\frac{\alpha_{2} \theta_{2}\left(\alpha_{1} \theta_{1} Q_{1}-\alpha_{1} \theta_{1} Q_{2}+t\right)}{\alpha_{1} \theta_{1}+\alpha_{2} \theta_{2}}, & t<\left(Q_{1}+Q_{2}\right) \alpha_{1} \theta_{1} \\ 0 & \text { otherwise }\end{array}\right.$

The total costs for each country are then calculated by substituting $a$ and $p$ into the equations

$C_{1}=c_{1}\left(Q_{1}+a, \theta_{1}\right)-a p$

and

$C_{2}=c_{2}\left(Q_{2}+a, \theta_{2}\right)-a p$.

Uncertainty is modeled so that abatement costs of both countries are either fully independent or fully correlated. In reality, deviations from expectations about abatement costs in two countries would usually be partially correlated, so our modeling of uncertainty can be seen as boundary cases. Negative correlation is generally not to be expected, because "surprises" in abatement costs are likely to be positively correlated between different countries or regions.

To see this, consider typical reasons why actual abatement costs may deviate from exante expectations. This may arise because technologies are less or more available or more or less costly than expected; because prices for energy and other production inputs differ from 
expectations; or because the behavior of businesses and individuals in response to emissions prices differs from that expected. In all of these cases, there is reason to expect that the surprise would occur and point in the same direction in all jurisdictions (or in both countries in our analysis), though the strength of its effect may be very different. Uncertainties that stem from policy making - for example, changes in policies that have interaction with emissions pricing - can be considered as largely independent between countries; again there is no reason to suspect that they would be negatively correlated.

In the default scenarios we assume the uncertainty parameters $\theta_{i}$ are log-normally distributed with a scale parameter of $\sigma=0.4$, and we also test other parameter values. The effect of these scale parameters on the probability distributions for $\theta_{i}$ are shown in Figure 2 .

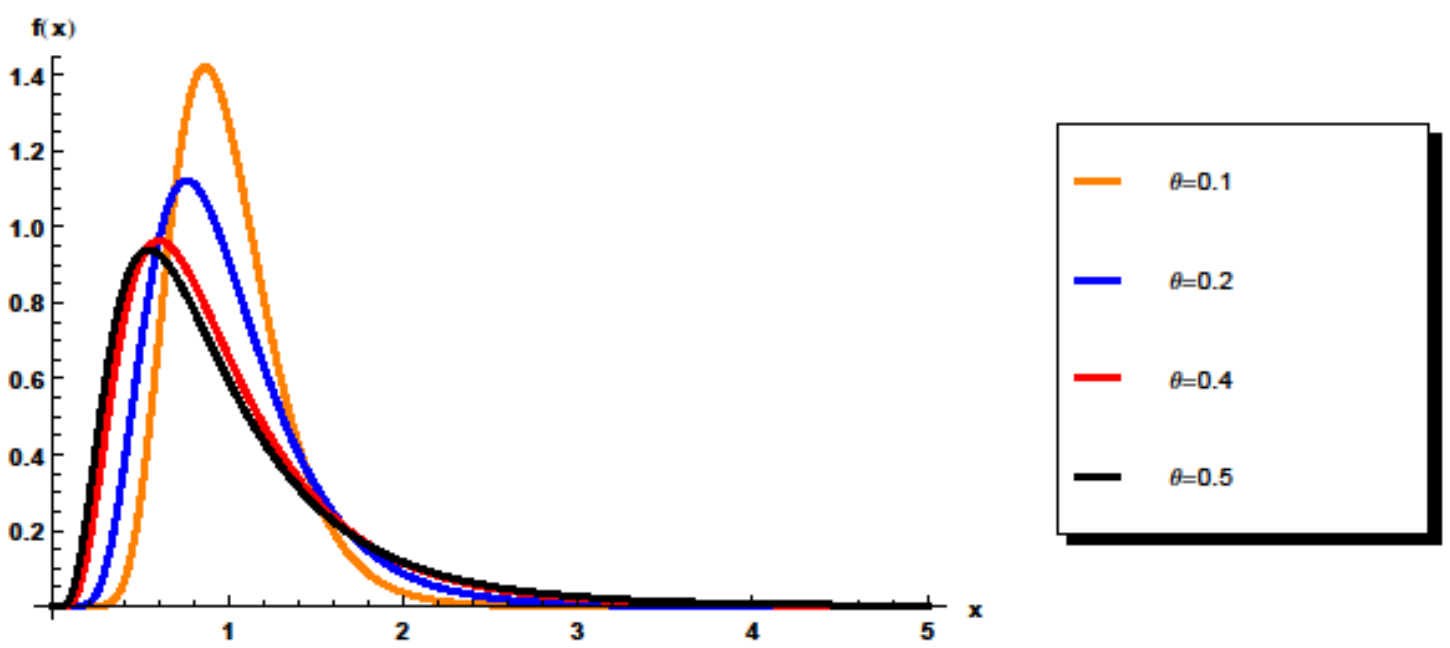

Figure 2: Example of log-normal distributions for different scale parameters $\sigma$ to describe the probability distributions for the random variables $\theta_{i}$ as applied in the model.

\section{Application of the model}

In this section, different sets of parameters are applied to the model by numerically evaluating expected costs for both countries under uncertainty using the software package Wolfram 
Mathematica 8. In a first step, costs are evaluated assuming ex-ante identical countries, i.e., countries of same size and having the same parameters for uncertainty. The model application will focus on the effect of an additional tax introduced in country 1 on top of an existing capand-trade scheme on expected costs for both countries, and the distribution of abatement effort between the two countries. To do so, different levels of $t_{1}$. and overall ambition in producing the public good are considered.

In a second step, the model application is expanded from the case of identical countries to a case where parameters are chosen so that they mimic the situation in the EU ETS. While these countries are covered by a joint cap-and-trade scheme, the ambitions of climate and energy policies differ strongly between countries. Many EU member states introduced policies that aim to set incentives for greenhouse-gas reduction in addition to the EU ETS. Examples, as mentioned in the introduction of this paper, include the UK carbon floor price, existing carbon taxes in several EU states, and the German renewable feed-in tariff scheme.

The objective of the approach taken here is not to generate empirically reliable figures on the effect of climate policy actions taken by EU member states, but to illustrate the partial effects of those policies on abatement and expected costs, in the situation where countries and sectors which are subject to the additional tax are not identical as in the simplified standard assumption. We do not claim to generate results which actually reflect the situation in the EU ETS because of the static partial equilibrium structure of the model, and choice of simple quadratic abatement cost functions (linear marginal abatement costs).

\section{Ex-ante identical countries}

Suppose that both countries are ex-ante identical, i.e., are of same size, have the same abatement costs $\left(\alpha_{1}=\alpha_{2}=1\right)$, and take on the same targets $\left(Q_{1}=Q_{2}=1\right)$. We compare 
expected costs under pure cap-and-trade without the additional tax $\left(t_{1}=0\right)$ to the situation when country 1 levies an additional charge on top of the allowance price $\left(t_{1}>0\right)$

Figure 3 plots expected costs and amounts of emissions reductions as a function of the tax rate under three different assumptions about uncertainty: (1) that there is no uncertainty in the cost function; (2) uncertainty in cost is perfectly correlated for both countries; and (3) uncertainties in cost are independent.

As derived theoretically above, abatement costs increase for country 1 and decrease for country 2 as $t_{1}$ is increased. Under certainty, a corner solution will be reached at $t_{1}=2$. In this case, costs of country 2 become zero. Under certainty and $t_{1}=0$ (the reference case of pure cap-and-trade), the permit price would be 1 . The tax rates in the figures below should be interpreted relative to this price. Abatement costs are lower when costs are correlated because individual realizations will include situations where different costs lead to gains from allowance trading.

Figure 3a also plots the expected amount of the public good that will be produced (solid/dashed black line). The overall quantity targets under cap-and-trade are set to equal $Q_{1}+Q_{2}=2$ in this application. The amount of expected abatement (dashed black line) slowly increases as $t_{1}$ increases, because of the increasing probability of a corner solution with greater production of the public good than targeted. 


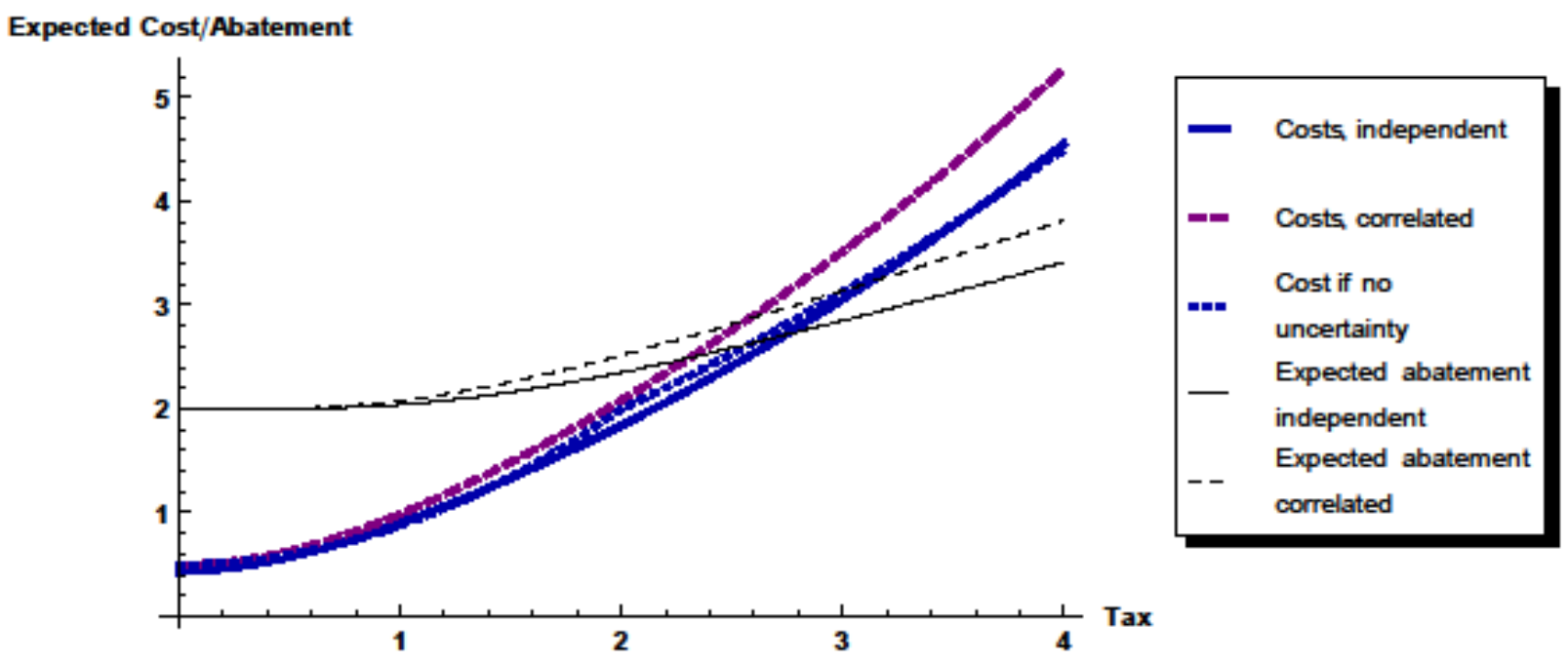

(a)

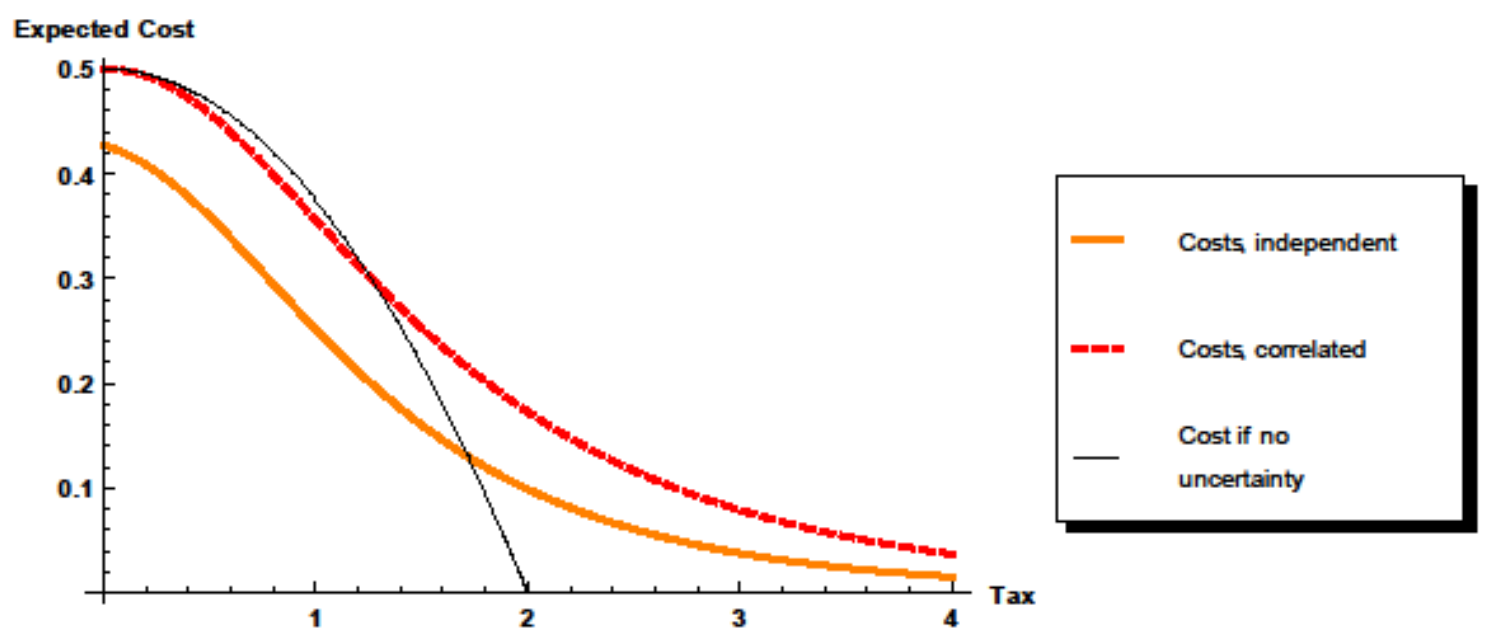

(b)

Figure 3: Expected costs for Country 1 (3a) and Country 2 (3b) as a function of the additional charge $t_{1}$ levied by Country 1 , with fully correlated and independent abatement costs, and assuming a scale parameter for uncertainty given by $\sigma=0.4$. Panel (3a) also shows expected abatement as a function of $t_{1}$.

Figure 4 shows independent and correlated expected total unit cost (or average cost) of abatement (sum of expected cost of both countries divided by expected abatement), as well as the expected allowance price and the expected number of traded allowances under correlated uncertainty. Unit cost and the number of traded allowances increase in $t_{1}$. The expected 
allowance price decreases as $t_{1}$ is increased. The elasticity of the allowance price under capand-trade with respect to the tax rate depends on relative abatement costs in both countries and the nature and extent of uncertainty.
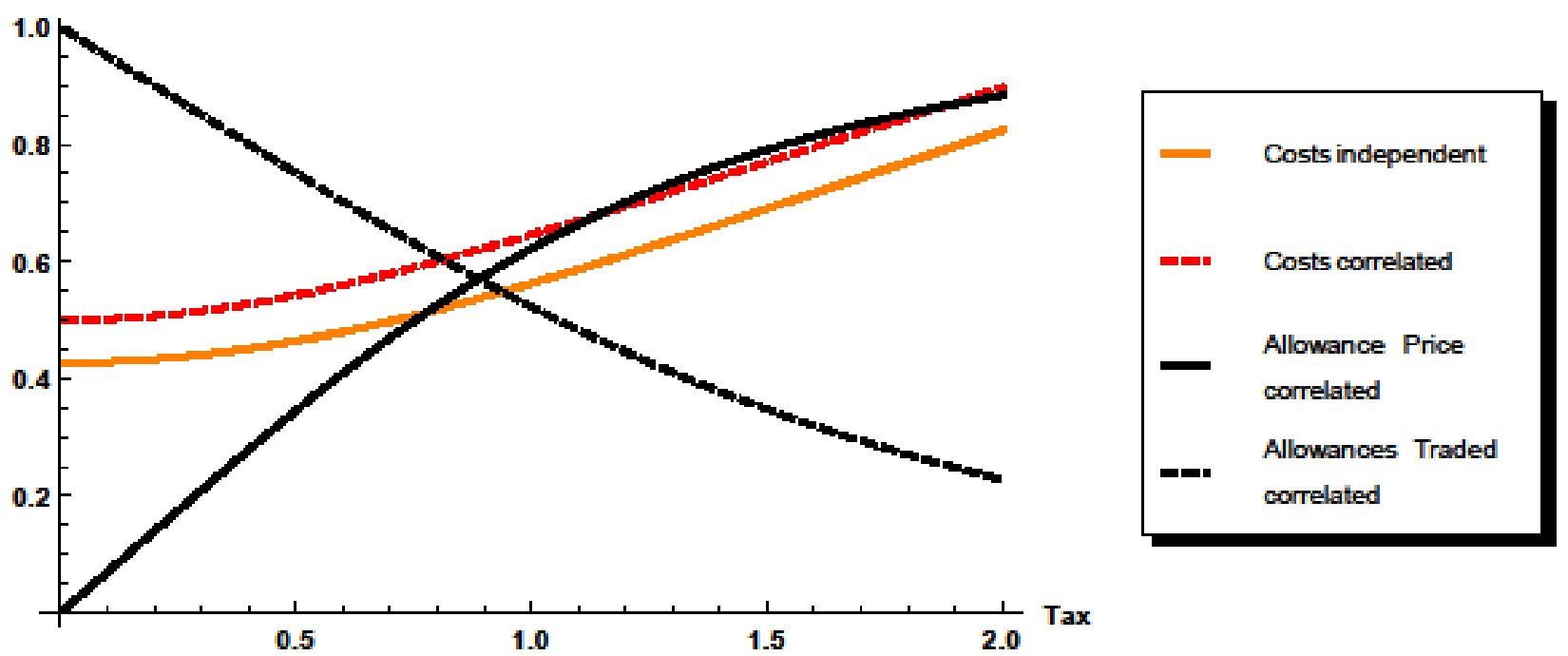

Figure 4: Expected independent and correlated total unit cost of abatement (average cost; sum of expected cost of both countries divided by expected abatement), expected correlated allowance price, and expected correlated allowances traded for ex-ante similar countries, assuming a scale parameter for uncertainty given by $\sigma=0.4$.

The results are of particular interest with respect to the EU ETS. Countries that participate in the EU ETS are largely independent with respect to designing additional domestic climate policies and fiscal policy in general. In many EU countries additional policies for abatement beyond the EU ETS where introduced. However, countries are not exante identical, but differ in terms of the size of regulated industries and abatement costs (for example through differences in technology). We will examine the case of the EU ETS in a stylized application to the EU's emissions trading scheme in the following section. 


\section{Stylized Application to the EU ETS}

Under the burden-sharing agreement (EU, 2002), each EU country has been assigned some amount of allowable emissions (an emissions target), which implicitly leads to abatement obligations ( $Q_{i}$ in the model above). The developments in the EU in the first and second trading period of the EU ETS (2007 to 2012) have revealed that there is significant uncertainty about demand for allowances by regulated companies and uncertainty about actual abatement costs (Hintermann, 2010). Emissions regulated by the EU ETS dropped significantly since 2008, leading to a considerable surplus and dramatically lower allowance prices.

A number of EU countries have introduced or reinforced additional climate policies parallel to the EU ETS. An example is the UK carbon "price floor," which works as an additional levy on each tonne of $\mathrm{CO}_{2}$ emitted by combustion installations regulated by the EU ETS. ${ }^{6}$ The policy matches directly to our model, with the UK being the "tax country."

The UK combustion sector represents approximately 10 percent of total emissions covered under the EU ETS, so country 1 will be much smaller than country 2. On average, changes in emissions in the sector are positively correlated to the rest of the EU ETS, with a positive correlation of about 0.5 .

Another example is the German renewable feed-in tariff scheme. While the policy offers subsidies for renewable energy instead of taxing greenhouse-gas emissions it still has an effect on the EU ETS by achieving some amount of emissions reductions in addition to that achieved by the EU ETS, and by thereby decreasing the allowance price within the ETS.

Since our model is a partial equilibrium model and uses only stylized assumptions about abatement costs and uncertainty, the results should not be interpreted as an actual

\footnotetext{
${ }^{6}$ A "price floor" normally describes a minimum price within an ETS, implemented for example through a reserve price at auction (Wood and Jotzo, 2011). The UK scheme arrangement is related but different to this standard version of a price floor.
} 
evaluation of the effects of the UK price floor arrangement. ${ }^{7}$ Our purpose is to give a broad indication about the magnitude of its effects, given in particular the relative magnitude of emissions covered by the "tax" and not covered.

To examine the effect of a "small country" (as part of the overall ETS) introducing an extra tax, we assume that the non-tax country 2 is ten times larger than country 1 . We use a country size parameter $S=10$, so that $Q_{1}=1$ and $Q_{2}=S Q_{1}=10$, and adjust country 2's abatement cost parameter by $\alpha_{2} / S$. We assume moderate uncertainty about abatement costs, with a scale parameter of $\sigma=0.2$, and that abatement costs are perfectly correlated. Abatement costs in country 2 are slightly higher than in country $1\left(\alpha_{1}=1, \alpha_{2}=1.1 / S\right)$.

Table 1 and Figure 5 show the allowance price under cap-and-trade; the number of traded allowances; abatement; and expected costs. If the tax were zero (pure cap-and-trade) the expected allowance price per unit of abatement would be 1.09. A small amount of allowances is sold from country 1 to country 2. Country 1's total costs are about 9 percent of country 2's costs. This is a least-cost situation where country 2 is large relative to country 1 and has higher abatement costs.

As country 1 introduces a tax, the price of allowances decreases. At tax rate $t=0.55$ (about 50 percent of the allowance price) the expected price is about 5 percent less than it is when $t_{1}=0$. If country 1 sets the tax rate approximately equal to the cap-and-trade price, allowance prices decrease by about 9 percent relative to $t_{1}=0$. Since country 1 is considerably smaller than country 2, the effect of the tax on the allowance price is relatively small. The amount of allowances sold from country 1 to country 2 increases as $t$ is increased. This is because a greater share of the overall abatement is produced in country 1 on account of the tax.

\footnotetext{
${ }^{7}$ We assume quadratic abatement cost functions for both countries and a log-linear probability distribution to calculate expected values by numerical integration using the software package Wolfram Mathematica. For a detailed description of the parameterized model and the structure of uncertainty please see Wood et al. (2013, pp. 4-7)
} 
Since more abatement occurs in country 1 for $t_{1}=0$, the total abatement costs of country 1 increase as $t_{1}$ increases. While the feedback of the tax on the allowance price is moderate if country 1 is small, cost increases in country 1 are considerable. For a tax of about 50 percent of the allowance price, costs for country 1 increase by about 37 percent relative to $t_{1}=0$. If the tax is set to approximately equal to the allowance price $\left(t_{1}=1\right)$ country 1 's domestic abatement costs will be more than twice as much as they are when $t_{1}=0$. Cost increases in country 1 are accompanied by small cost decreases in country 2 . This is because country 2 can purchase allowances from country 1 and allowance prices decrease as $t_{1}$ is increased. Combined costs increase relative to the situation without a tax because country 1's cost increases cannot be offset by cost decreases in country 2 .

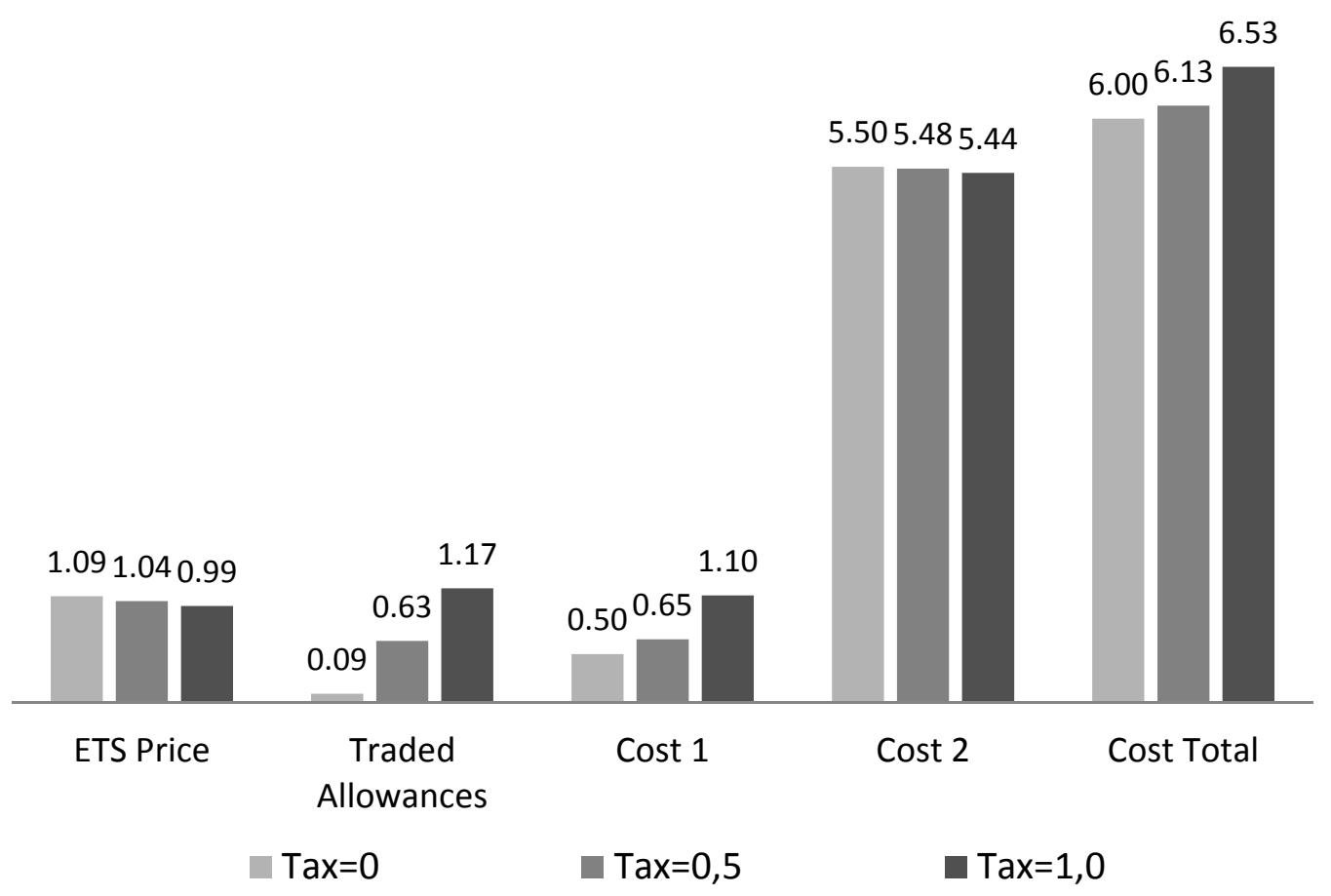

Figure 5: Expected values for ETS allowance price, number of traded allowances, cost for Country 1 and Country 2, and total cost for tax rates 0 , 0.5, and 1 in Country 1 (see Table 1 for details).

The model application showed that the introduction of an additional tax under capand-trade and uncertain abatement costs will have a moderate effect on prices and total abatement costs if the country or sector covered by the tax is small relative to the remaining 
countries or sectors, and if the tax rate is small relative to the allowance price. For example, a tax rate of 10 percent of the allowance price in the model application leads to a decrease in the allowance price of about 1 percent and an increase in total costs of about 0.1 percent. If country 1 is small, it further is unlikely that a corner solution will be reached (all of the combined abatement task fulfilled by the tax in country 1 alone).

\section{Allowance price elasticity, country size, and uncertainty}

In this subsection we examine the elasticity of the cap-and-trade price with respect to the tax rate, and its relationship to country size and uncertainty. Under the parameterization of this paper, elasticities are not constant. This approach helps provide an understanding of how prices are affected by country size and correlations in uncertainty parameters. The elasticity of the cap-and-trade price with respect to the tax thus gives an indication of efficiency implications of the additional tax. In our simple model (omitting effects of innovation and other long-run effects), the additional tax always leads to additional costs for the country that levies the tax in addition to the cap-and-trade scheme. The actual extent of additional costs, however, depends on the feedback of the unilateral tax on the joint cap-and-trade scheme, i.e., the elasticity of the allowance price with respect to the tax.

We calculate expected prices by numerical integration for tuples of $S=1,2, \ldots, 10$ and $\sigma=0.05,0.1, \ldots, 0.5 .^{8}$ For each $S$, $\sigma$ tuple, prices are evaluated for $t=0.1,0.11, \ldots, 1$ so that price-tax combinations are obtained for each of the $S, \sigma$ tuples. To estimate the average elasticity of cap-and-trade prices with respect to the tax we consider a simple linear elasticity model of the form

$$
\log \left(\text { price }_{i}\right)=\beta_{0}+\beta_{1} \log \left(\operatorname{tax}_{i}\right)+u_{i}
$$

\footnotetext{
${ }^{8}$ For detailed information on how uncertainty is modeled, see pp. 5-7 of Wood et al. (2013)
} 
The linear elasticity model is estimated for $S, \sigma$ tuples to obtain elasticity $\beta_{1, S, \sigma}$. If the tax in country 1 increases by 1 percent, the price in the joint cap-and-trade scheme changes by $\beta_{1, S, \sigma}$ percent.

Tables 2 and 3 show elasticity $\beta_{1, S, \sigma}$ for independent and correlated uncertainty. The elasticity of the price under cap-and-trade with respect to the tax is dependent on relative country size $S$ and on the uncertainty scale parameter $\sigma$. For independent abatement costs, a larger uncertainty scale parameter leads to higher sensitivity of the cap-and-trade price with respect to changes in the tax rate. If country 1 is small, the effect of changes in the tax rate tend to be relatively low. For $S=10$ and $\sigma=0.2$, a 1 percent increase in the tax rate would lead to an average decrease of 0.048 percent in the cap-and-trade price.

For perfectly correlated abatement costs, the elasticity of the price with respect to the tax is in general lower than when abatement costs are independent, while the effect of uncertainty is reversed. The elasticity is slightly lower for higher values of the scale parameter $\sigma$. In particular for the case of country 1 being relatively large both countries can encounter high cost if there is perfectly correlated uncertainty. Therefore the effect of the tax on the price can be less pronounced for larger values of $\sigma$, i.e., since the tax rate was assumed not to exceed $t=1$ in this application. With respect to country size, the previous results also hold in the case of correlated uncertainty, where the elasticity of the price with respect to the tax is rather low if $S$ is large and country 1 is small relative to country 2.

For a case like the UK power sector, it might be reasonable to assume $S=10$ with uncertainty and some positive correlation (not necessarily perfect correlation). As Tables 2 and 3 show, there is not much difference between the cases of perfectly correlated and uncorrelated abatement costs. The model results indicate that the elasticity of the cap-andtrade price with respect to the tax (for $t=0.1,0.11, \ldots, 1$ ) will be between -0.040 and -0.058 if a "small country” introduces a tax. 


\section{Discussion and policy implications}

Our stochastic partial equilibrium model demonstrates that unilateral additional efforts for public good production (i.e., an additional unilateral tax) under a joint cap-and-trade scheme will cause excess costs and will in most cases not yield additional production of the public good. Two cases can be distinguished.

In the interior solution the cap-and-trade price will be greater than zero in the presence of the tax. In this situation more abatement efforts are borne by country 1 . Costs for country 1 increase accordingly, while costs for country 2 decrease. Total costs (the sum of cost of both countries) will increase since increased costs of country 1 cannot be offset by cost savings in country 2. There is no additional production of the public good (abatement) in the interior solution since the joint quantity target $Q_{1}+Q_{2}$ is binding.

In the corner solution, all abatement is borne by country 1 and there is no need for further abatement by country 2 . The allowance price is zero in the corner solution.

Expected costs for country 1 and expected total costs will in most cases be considerably higher than with pure cap-and-trade without the additional tax. The allowance price decreases, and extra costs increase, as the tax rate is increased.

The stochastic modeling showed that country size and the magnitude of uncertainty about abatement costs are important determinants of the effect of the tax on the allowance price. In section 3 we examined the case of a small country with additional tax. The application showed that the introduction of the tax will lead to increased expected allowance sales from country 1 to country 2 (see table 1 ), so that public good production (and cost) is reallocated from country 2 to country 1 . Expected costs for country 1 increase considerably, while the cost of country 2 decrease slightly, and combined costs increase due to the divergence in marginal costs. 
The elasticity of the allowance price with respect to the tax for different country size and levels of uncertainty was examined in section 3. For the chosen parameter set, the effect of country size on the elasticity is more pronounced than for the level of uncertainty. Expected allowance prices decrease as the tax is increased. If country 1 is small, the effect of the tax on the allowance price is moderate.

One reason for country 1 to introduce an additional tax could be that the country aims to speed up the decarburization of the economy and to set stronger incentives for innovation (relative to country 2). Such aspects are omitted in our model, but may be of importance in theory and practice, if stronger action is viewed as improving dynamic efficiency or desired for other reasons. Carbon pricing can offer strong incentives for innovation, and again "country size” is an important determinant of the prospects for reaping dynamic efficiency gains (Downing and White, 1986; Milliman and Prince, 1989). The "stringency" of regulation can be important for the extent of innovation, as shown for the EU ETS and the power sector by Rogge et al. (2011). Innovation research in the field of environmental economics has further emphasized the dual aspect of environmental regulation on externalities. While negative externalities, such as pollution, are decreased, the incentives for innovation can be interpreted as a positive externality caused by a price (Rennings, 2000).

Our model does not account for the effects of innovation. However, for additional policies in one country to be globally welfare enhancing, the positive innovation externality must at least outweigh excess costs of the policy. Innovation activity can be expected to increase in the country that introduces the additional policy, but could decrease in the other country on account of the lower allowance price. ${ }^{9}$ This could lead to overall greater innovation activity, for example if the greater incentives in the country with the additional policy allow the crossing of an "innovation threshold" that would not be reached under a pure

\footnotetext{
${ }^{9}$ This argument is related to dynamic efficiency of regulation discussed in Downing and White (1986).
} 
cap-and-trade scheme. Whether and under which conditions this may hold is an empirical question beyond the scope of this paper.

\section{$5 \quad$ Conclusion}

We have examined the introduction of additional national policies for public good production, specifically a national carbon tax in one country, under a joint cap-and-trade scheme of two countries with fixed joint quantity targets. Examples for such additional policies would be the UK carbon price floor or the German renewable feed-in tariff scheme in combination with environmental regulation by the EU Emissions Trading Scheme. Both unilateral policies aim at the utility sector, which already is regulated by the EU ETS.

In most cases the additional tax will not lead to additional abatement beyond the fixed quantity target. Additional abatement will only occur in the case when a corner solution is reached. In this case all abatement is undertaken by the country with the extra tax, the allowance price under cap-and-trade will be zero, and expected costs are considerably higher.

Countries may pursue dynamic efficiency objectives in strengthening their domestic effort, including through fostering the innovation effort. We do not evaluate this aspect, rather we investigate the effect of relative country size and magnitude of abatement cost uncertainty.

The expected allowance price decrease as the tax rate is increased. The effect depends on the relative size of the country that introduces the additional policy and the extent of uncertainty. The smaller the country with additional policy is, the smaller will be the feedback of the tax on the allowance price. Larger uncertainty will lead to a stronger feedback effect if abatement costs are independent and will lead to smaller feedback effect if costs are perfectly correlated.

Our model results highlight the importance of interactions between domestic climate policies and overarching mechanisms such the EU ETS. Countries may have specific national objectives in introducing additional policy mechanisms domestically. However such 
additional national policies will generally not result in overall increased effort, and will result in higher overall static abatement cost. It is possible that there are gains in dynamic efficiency, for example through enhanced innovation effort in the country with the additional policies. Whether and under which conditions these exist and outweigh the additional static costs that arise from diverging marginal costs of abatement remains an open question.

\section{References:}

Baumol, W.J., 1972. On Taxation and the Control of Externalities. American Economic Review 62, 307-322.

Baumol, W.J., Oates, W.E., 1971. The use of standards and prices for protection of the environment. The Swedish Journal of Economics 73, 42-54.

Baumol, W.J., Oates, W.E., 1988. The Theory of Environmental Policy, 2nd Editio. ed. Cambridge University Press, Cambridge.

Boeters, S., Koornneef, J., 2011. Supply of renewable energy sources and the cost of EU climate policy. Energy Economics 33, 1024-1034.

Böhringer, C., Löschel, A., Moslener, U., Rutherford, T.F., 2009a. EU climate policy up to 2020: An economic impact assessment. Energy Economics 31, 295-305.

Böhringer, C., Rutherford, T.F., Tol, R.S.J., 2009b. THE EU 20/20/2020 targets: An overview of the EMF22 assessment. Energy Economics 31, 268-273.

Bovenberg, A.L., 1999. Green tax reforms and the double dividend: an updated reader's guide. International Tax and Public Finance 6, 421-443.

Bovenberg, A.L., Goulder, L.H., 1996. Optimal Environmental Taxation in the Presence of Other Taxes: General-Equilibrium Analyses. American Economic Review 86, 985-1000.

Bovenberg, A.L., van der Ploeg, F., 1994. Environmental policy, public finance and the labour market in a second-best world. Journal of Public Economics 55, 349-390.

Downing, P.B., White, J.L., 1986. Innovation in pollution control. Journal of Environmental Economics and Management 13, 18-29.

EU, 2002. Directive 2002/358/EC: Council Decision of 25 April 2002 concerning the approval, on behalf of the European Community, of the Kyoto Protocol to the United Nations Framework Convention on Climate Change and the joint fulfilment of commitments thereunder. Luxembourg.

Hagem, C., Westskog, H., 1998. The design of a dynamic tradeable quota system under market imperfections. Journal of Environmental Economics and Management 36, 89-107.

Hahn, R.W., 1984. Market power and transferable property rights. The Quarterly Journal of Economics 99, 753765.

Hahn, R.W., Stavins, R.N., 2011. The Effect of Allowance Allocations on Cap-and-Trade System Performance. Journal of Law and Economics 54, 267-294. 
Hartman, R.S., Wheeler, D., Singh, M., 1997. The cost of air pollution abatement. Applied Economics 29, 759774.

Hintermann, B., 2010. Allowance price drivers in the first phase of the EU ETS. Journal of Environmental Economics and Management 59, 43-56.

IEA, 2013. Energy Policies of IEA Countries: Germany 2013 Review. International Energy Agency, Paris.

McKitrick, R., 1999. A Derivation of the Marginal Abatement Cost Curve. Journal of Environmental Economics and Management 37, 306-314.

Milliman, S.R., Prince, R., 1989. Firm incentives to promote technological change in pollution control. Journal of Environmental Economics and Management 17, 247-265.

Montgomery, W.D., 1972. Markets in Licenses and Efficient Pollution Control Programs. Journal of Economic Theory 5, 395-418.

OECD, 2013. Taxing Energy Use: A Graphical Analysis. OECD Publishing.

Pezzey, J.J.C.V., Jotzo, F., 2012. Tax-versus-trading and efficient revenue recycling as issues for greenhouse gas abatement. Journal of Environmental Economics and Management 64, 230-236.

Rennings, K., 2000. Redefining innovation - eco-innovation research and the contribution from ecological economics. Ecological Economics 32, 319-332.

Rogge, K.S., Schneider, M., Hoffmann, V.H., 2011. The innovation impact of the EU Emission Trading System: Findings of company case studies in the German power sector. Ecological Economics 70, 513-523.

Sinn, H.-W., Schmoltzi, U., 1981. Eigentumsrechte, Kompensationsregeln und Marktmacht: Anmerkungen zum Coase Theorem. Jahrbuecher für Nationalökonomie und Statistik 196, 97-117.

Stavins, R.N., 1995. Transaction Costs and Tradeable Permits. Journal of Environmental Economics and Management 29, 133-148.

Toke, D., 2011. UK Electricity Market Reform - revolution or much ado about nothing? Energy Policy 39, 7609-7611.

Weitzman, M.L., 1974. Prices vs. Quantities. The Review of Economic Studies 41, 477-491.

Wood, P.J., Heindl, P., Jotzo, F., Löschel, A., 2013. Linking Price and Quantity Pollution Controls under Uncertainty. CEEP Working Paper, Centre for Climate Economics and Policy, Crawford School of Public Policy, Australian National University No. 1302.

Wood, P.J., Jotzo, F., 2011. Price floors for emissions trading. Energy Policy 39, 1746-1753. 
Table 1: Numerical evaluation of an additional tax under a joint cap-and-trade if Country 2 is 10 times larger than Country 1 ( $\mathrm{S}=10)$, if there is intermediate uncertainty about abatement costs (Sigma=0.2), and Country 2's abatement cost parameter is slightly higher than Country 1 's $\left(\alpha_{1}=\right.$ $1, \alpha_{2}=1.1$ ). Abatement costs are assumed to be perfectly correlated. All values (other than the tax rate) are expectations.

\begin{tabular}{|c|c|c|c|c|c|c|c|c|c|c|c|c|}
\hline Tax & Price & $\begin{array}{l}\text { Price } \\
\text { Change \% }\end{array}$ & $\begin{array}{l}\text { Tax/Price } \\
\text { Ratio }\end{array}$ & $\begin{array}{l}\text { Allowances } \\
\text { Traded }\end{array}$ & $\begin{array}{l}\text { Allowances } \\
\text { Change \% }\end{array}$ & Abatement & Cost 1 & $\begin{array}{l}\text { Cost } 1 \\
\text { Change \% }\end{array}$ & Cost 2 & $\begin{array}{l}\text { Cost } 2 \\
\text { Change \% }\end{array}$ & Total cost & $\begin{array}{l}\text { Total Cost } \\
\text { Change \% }\end{array}$ \\
\hline 0.00 & 1.090 & - & - & 0.090 & - & 11 & 0.496 & - & 5.500 & - & 5.995 & - \\
\hline 0.05 & 1.085 & -0.45 & 0.046 & 0.144 & 60 & 11 & 0.498 & 0.39 & 5.499 & -0.01 & 5.996 & 0.02 \\
\hline 0.10 & 1.080 & -0.91 & 0.093 & 0.198 & 120 & 11 & 0.503 & 1.38 & 5.498 & -0.03 & 6.000 & 0.09 \\
\hline 0.15 & 1.075 & -1.36 & 0.140 & 0.252 & 180 & 11 & 0.511 & 2.97 & 5.497 & -0.05 & 6.007 & 0.20 \\
\hline 0.20 & 1.070 & -1.82 & 0.187 & 0.306 & 240 & 11 & 0.521 & 5.15 & 5.496 & -0.07 & 6.016 & 0.35 \\
\hline 0.25 & 1.065 & -2.27 & 0.235 & 0.360 & 300 & 11 & 0.535 & 7.94 & 5.494 & -0.10 & 6.028 & 0.55 \\
\hline 0.30 & 1.060 & -2.73 & 0.283 & 0.414 & 360 & 11 & 0.552 & 11.32 & 5.492 & -0.14 & 6.043 & 0.80 \\
\hline 0.35 & 1.055 & -3.18 & 0.332 & 0.468 & 420 & 11 & 0.572 & 15.30 & 5.490 & -0.18 & 6.060 & 1.09 \\
\hline 0.40 & 1.050 & -3.64 & 0.381 & 0.523 & 480 & 11 & 0.595 & 19.89 & 5.487 & -0.22 & 6.080 & 1.42 \\
\hline 0.45 & 1.045 & -4.09 & 0.430 & 0.577 & 540 & 11 & 0.620 & 25.07 & 5.485 & -0.27 & 6.103 & 1.80 \\
\hline 0.50 & 1.041 & -4.55 & 0.481 & 0.631 & 600 & 11 & 0.649 & 30.85 & 5.482 & -0.32 & 6.128 & 2.22 \\
\hline 0.55 & 1.036 & -5.00 & 0.531 & 0.685 & 660 & 11 & 0.681 & 37.23 & 5.478 & -0.38 & 6.156 & 2.68 \\
\hline 0.60 & 1.031 & -5.45 & 0.582 & 0.739 & 720 & 11 & 0.715 & 44.21 & 5.475 & -0.45 & 6.186 & 3.19 \\
\hline 0.65 & 1.026 & -5.91 & 0.634 & 0.793 & 780 & 11 & 0.753 & 51.78 & 5.471 & -0.52 & 6.219 & 3.75 \\
\hline 0.70 & 1.021 & -6.36 & 0.686 & 0.847 & 840 & 11 & 0.793 & 59.96 & 5.467 & -0.59 & 6.255 & 4.35 \\
\hline 0.75 & 1.016 & -6.82 & 0.738 & 0.901 & 900 & 11 & 0.837 & 68.73 & 5.463 & -0.67 & 6.294 & 4.99 \\
\hline 0.80 & 1.011 & -7.27 & 0.791 & 0.955 & 960 & 11 & 0.883 & 78.11 & 5.458 & -0.75 & 6.335 & 5.68 \\
\hline 0.85 & 1.006 & -7.73 & 0.845 & 1.009 & 1020 & 11 & 0.933 & 88.08 & 5.453 & -0.84 & 6.379 & 6.41 \\
\hline 0.90 & 1.001 & -8.18 & 0.899 & 1.063 & 1080 & 11 & 0.985 & 98.65 & 5.448 & -0.94 & 6.425 & 7.18 \\
\hline 0.95 & 0.996 & -8.64 & 0.954 & 1.117 & 1140 & 11 & 1.041 & 109.82 & 5.443 & -1.03 & 6.475 & 8.00 \\
\hline 1.00 & 0.991 & -9.09 & 1.009 & 1.171 & 1200 & 11 & 1.099 & 121.59 & 5.437 & -1.14 & 6.526 & 8.87 \\
\hline
\end{tabular}


Table 2: Elasticity of the allowance price for changes in the tax rate for different country size (S) and uncertainty scale parameter ( $\sigma$ ). Cost uncertainty is independent.

\begin{tabular}{crrrrrrrrrr}
$\mathrm{S}$ & $\sigma$ & 0.05 & 0.1 & 0.15 & 0.2 & 0.25 & 0.3 & 0.35 & 0.4 & 0.45 \\
\hline 1 & -0.30082 & -0.31017 & -0.31804 & -0.32439 & -0.32945 & -0.33349 & -0.33674 & -0.33936 & -0.34149 & -0.34323 \\
2 & -0.17815 & -0.18478 & -0.19114 & -0.19716 & -0.20276 & -0.20791 & -0.21263 & -0.21693 & -0.22085 & -0.22442 \\
3 & -0.12684 & -0.13185 & -0.13668 & -0.14136 & -0.14586 & -0.15015 & -0.15423 & -0.15809 & -0.16173 & -0.16516 \\
4 & -0.09854 & -0.10256 & -0.10646 & -0.11025 & -0.11392 & -0.11747 & -0.12089 & -0.12418 & -0.12734 & -0.13036 \\
5 & -0.08058 & -0.08395 & -0.08722 & -0.0904 & -0.09349 & -0.0965 & -0.09942 & -0.10225 & -0.10499 & -0.10763 \\
6 & -0.06816 & -0.07106 & -0.07389 & -0.07663 & -0.07931 & -0.08191 & -0.08445 & -0.08692 & -0.08933 & -0.09166 \\
7 & -0.05907 & -0.06161 & -0.0641 & -0.06652 & -0.06887 & -0.07118 & -0.07342 & -0.07562 & -0.07775 & -0.07984 \\
8 & -0.05211 & -0.05438 & -0.0566 & -0.05876 & -0.06088 & -0.06294 & -0.06496 & -0.06693 & -0.06885 & -0.07073 \\
9 & -0.04663 & -0.04867 & -0.05068 & -0.05263 & -0.05455 & -0.05642 & -0.05825 & -0.06004 & -0.06179 & -0.0635 \\
10 & -0.04219 & -0.04405 & -0.04588 & -0.04767 & -0.04941 & -0.05113 & -0.0528 & -0.05444 & -0.05605 & -0.05762 \\
\hline
\end{tabular}

Table 3: Elasticity of the allowance price for changes in the tax rate for different country size (S) and uncertainty scale parameter ( $\sigma$ ). Cost uncertainty is perfectly correlated.

\begin{tabular}{rrrrrrrrrrr}
$\mathrm{S}$ & $\sigma$ & 0.05 & 0.1 & 0.15 & 0.2 & 0.25 & 0.3 & 0.35 & 0.4 & 0.45 \\
\hline 1 & -0.29073 & -0.29041 & -0.28934 & -0.28757 & -0.28531 & -0.28274 & -0.27999 & -0.27717 & -0.27433 & -0.27154 \\
2 & -0.17129 & -0.17128 & -0.17126 & -0.17116 & -0.17096 & -0.17065 & -0.17024 & -0.16974 & -0.16918 & -0.16857 \\
3 & -0.12166 & -0.12166 & -0.12166 & -0.12165 & -0.12163 & -0.12158 & -0.12150 & -0.12139 & -0.12126 & -0.12110 \\
4 & -0.09438 & -0.09438 & -0.09438 & -0.09438 & -0.09437 & -0.09437 & -0.09435 & -0.09432 & -0.09429 & -0.09425 \\
5 & -0.07711 & -0.07711 & -0.07711 & -0.07711 & -0.07710 & -0.07710 & -0.07710 & -0.07710 & -0.07709 & -0.07708 \\
6 & -0.06518 & -0.06518 & -0.06518 & -0.06518 & -0.06518 & -0.06518 & -0.06518 & -0.06518 & -0.06519 & -0.06519 \\
7 & -0.05646 & -0.05646 & -0.05646 & -0.05646 & -0.05646 & -0.05646 & -0.05646 & -0.05646 & -0.05646 & -0.05647 \\
8 & -0.04979 & -0.04979 & -0.04979 & -0.04979 & -0.04979 & -0.04979 & -0.04979 & -0.04980 & -0.04980 & -0.04981 \\
9 & -0.04453 & -0.04453 & -0.04453 & -0.04453 & -0.04453 & -0.04453 & -0.04454 & -0.04454 & -0.04454 & -0.04455 \\
10 & -0.04028 & -0.04028 & -0.04028 & -0.04028 & -0.04028 & -0.04028 & -0.04028 & -0.04029 & -0.04029 & -0.04030 \\
\hline
\end{tabular}

